\title{
Quality of analytical performance in inherited metabolic disorders: the role of ERNDIM
}

\section{B. Fowler • A. Burlina • V. Kožich • C. Vianey-Saban}

Published online: 25 January 2009

(C) SSIEM and Springer 2009

Erratum to: J Inherit Metab Dis 2008; 31(6): 680-689 DOI 10.1007/s10545-008-1025-4

The affiliation of Dr Kožich should read:

Institute of Inherited Metabolic Diseases, Charles University in Prague-First Faculty of Medicine, Prague, Czech Republic http://dx.doi.org/10.1007/s10545-008-1025-4

B. Fowler $(\square)$

Metabolic Unit, University Children's Hospital,

Roemergasse 8, Basel 4058, Switzerland

e-mail: Brian.Fowler@unibas.ch

\section{A. Burlina}

Department of Pediatrics, University of Padua,

Padova, Italy

\section{Kožich}

Institute of Inherited Metabolic Diseases,

Charles University in Prague-First Faculty of Medicine,

Prague, Czech Republic

C. Vianey-Saban

Centre de Biologie et Pathologie Est,

Groupier Hospitalier Est, Bron, France 